\title{
Correction to: Biores Open Access 2016;5:137-145
}

In the 2016 volume of BioResearch Open Access (vol. 5, no. 1; 137-145), the article entitled "Microbiota and Neurological Disorders: A Gut Feeling" by Moos et al. requires a correction.

Reference 98 was incorrectly cited in the first paragraph of page 142; this should be reference 194, which was inadvertently omitted from the article. The corrected text and newly added reference are below:

The mouth, being an extension of the digestive tract, presents a readily accessible diagnostic site for the early detection of potential unhealthy pathogens resident in the gut. Salivanomics is a rapidly emerging tool in the arsenal of salivary diagnostics. ${ }^{194}$ Collecting saliva or swabbing the inside cheek of the mouth is noninterventional, making it a highly attractive diagnostic procedure, particularly for infants and young children. It is not unlikely that regular visits to your dentist may soon be as important to your gut as it is to your oral hygiene, white teeth, and a nice smile.

194. Zhang Y, Sun J, Lin CC, et al. The emerging landscape of salivary diagnostics. Periodontol 2000. 2016;70:38-52.

The article has been corrected to reflect this change. The authors apologize for this error.

Publish in BioResearch Open Access

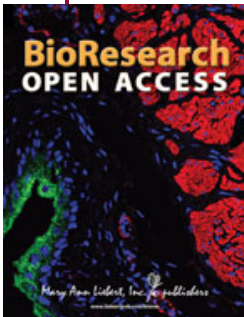

- Broad coverage of biomedical research

- Immediate, unrestricted online access

- Rigorous peer review

- Compliance with open access mandates

- Authors retain copyright

- Highly indexed

- Targeted email marketing

liebertpub.com/biores 